\title{
In situ formation by laser cladding of a TiC composite coating with a gradient distribution
}

\author{
Xiaolei $\mathrm{Wu}^{*}$ \\ Laboratory for Nonlinear Mechanics of Continuous Media, Institute of Mechanics, The Chinese Academy of Sciences, \\ Beijing 100080, People's Republic of China
}

Received 14 August 1998; accepted 6 February 1999

\begin{abstract}
An in situ method was developed to produce an Ni alloy composite coating reinforced by in situ reacted TiC particles with a gradient distribution, using one-step laser cladding with a pre-placed powder mixture on a 5CrMnMo steel substrate. Dispersed and ultra-fine TiC particles were formed in situ in the coating. Most of the TiC particles, with a marked gradient distribution, were uniformly distributed within interdendritic regions because of the trapping effect of the advancing solid-liquid interface. In addition, the $\mathrm{TiC}-\gamma-\mathrm{Ni}$ interfaces generated in situ were found to be free from any deleterious surface reaction. Finally, the microhardness also showed a gradient variation, with the highest value of $1250 \mathrm{Hv} 0.2$ and the wear properties of the coating were significantly enhanced. (C) 1999 Elsevier Science S.A. All rights reserved.
\end{abstract}

Keywords: Gradient layer; In situ formation of TiC; Laser cladding; Microstructure; Wear

\section{Introduction}

Ceramic particulate incorporation to provide a metal matrix composite (MMC) layer on various substrates by laser cladding is a relatively newly developed technique, in which an alloy powder of a desirable composition and a thin surface layer of the substrate materials are simultaneously melted and then rapidly solidified to form a dense coating metallurgically bonded to the base materials. Various ceramic-alloy systems, such as $\mathrm{SiC} / \mathrm{Co}-\mathrm{Cr}-\mathrm{W}, \quad \mathrm{Cr}_{2} \mathrm{O}_{3} / \mathrm{Ni}-\mathrm{Cr}-\mathrm{Mo}, \mathrm{WC} / \mathrm{Ni}-\mathrm{Cr}-\mathrm{Si}-\mathrm{B}$ and $\mathrm{TiC}(\mathrm{TiN}, \mathrm{TiB}) / \mathrm{Ni}$-based alloys, synthesized on traditional substrate materials have been studied [1-3].

The aim of the present investigation was to synthesize an in situ $\mathrm{TiC}$ dispersoid in an Ni alloy laser-clad coating on a $5 \mathrm{CrMnMo}$ steel substrate. A new method of in situ formation of $\mathrm{TiC}$ with a gradient distribution using one-step laser cladding is proposed. TiC particles are introduced by an in situ reaction of titanium and graphite during the laser cladding process, rather than the $\mathrm{TiC}$ particles being directly added into the lasermelted pool. The experimental results reveal that the optimum way to obtain submicron $\mathrm{TiC}$ particles with a uniform distribution is to induce their in situ formation

\footnotetext{
* Fax: +861062561284.

E-mail address: xlwu@ecc5.imech.ac.cn (X.Wu)
}

in the macrohomogenous molten pool during laser rapid solidification.

\section{Experimental}

A powder mixture of $\mathrm{Ni}$ alloy, titanium $(99.7 \%$ purity) and crystalline graphite (99.5\% purity) was used as the coating alloy. The titanium-graphite powder was 30 vol.\%. The titanium to carbon powder ratio corresponded to that of stoichiometric $\mathrm{TiC}$. The average size of the titanium and graphite particles was 2 and $4 \mu \mathrm{m}$, respectively. The Ni alloy powder possessed an average size of $20 \mu \mathrm{m}$ and its chemical composition (weight per cent) was $16 \mathrm{Cr}, 3.5 \mathrm{~B}, 4.5 \mathrm{Si}, 0.8 \mathrm{C}$, balanced by nickel. The substrate material was $5 \mathrm{CrMnMo}$ steel in a quenched and tempered condition.

Laser cladding was carried out with a $3 \mathrm{~kW}$ continuous wave $\mathrm{CO}_{2}$ laser to produce a series of single clad tracks without overlap. The processing parameters were $4-15 \mathrm{~mm} \mathrm{~s}^{-1}$ beam scanning speed, $3 \mathrm{~mm}$ beam diameter and $2 \mathrm{~kW}$ laser power. The mixed powders were painted on the substrate to give a thickness of about $0.8 \mathrm{~mm}$. Surface oxidation was prevented by argon.

The microstructure, composition and interface structure were observed by using a Neuphot 21 optical micro- 


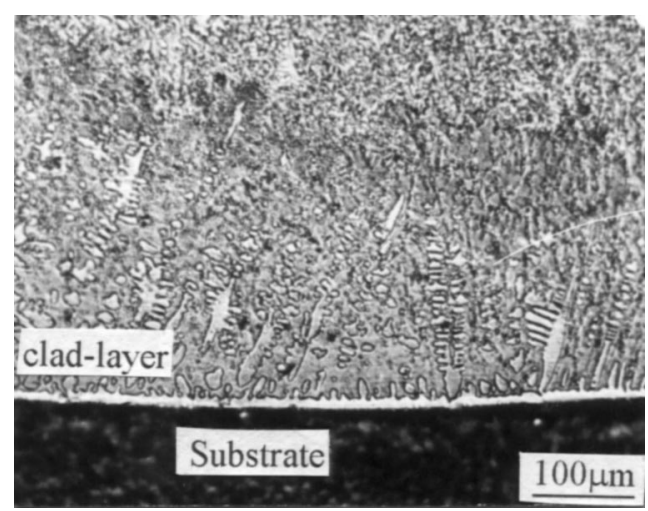

Fig. 1. Optical micrograph showing the transverse section of the laserclad composite coating at processing parameters of a $15 \mathrm{~mm} \mathrm{~s}^{-1}$ beam scanning speed, $3 \mathrm{~mm}$ beam diameter and $2 \mathrm{~kW}$ power.

scope, an Hitachi S570 scanning electron microscope, a Philips CM12 transmission electron microscope, and a Hitachi 9000 high resolution electron microscope (HREM). The volume fraction of TiC particles in the MMC layer was measured by a computerized image analysis method. Pin-on-disc abrasive wear was investigated using Falex friction and wear test machine. The specimens for the test were small pins of diameter $3 \mathrm{~mm}$ and length $6 \mathrm{~mm}$. Flint paper, with $\mathrm{Al}_{3} \mathrm{O}_{2}$ particle of -380 mesh size, was used as an abrasive. The specimen rotated at a speed of $100 \mathrm{rpm}$ with a load of $0.91 \mathrm{kgf}$, at the room temperature. Each test involved a sliding distance of $14.5 \mathrm{~m}$. The experiment was terminated after a $10 \mathrm{~min}$ time lapse, after which the wear loss was measured. The surface was first smoothed, because after the laser-clad processing all the specimens have surface roughness of at least a few tens of micrometers.

\section{Results and discussion}

\subsection{Microstructure}

Fig. 1 shows an optical micrograph of a cross-section of the laser-clad composite coatings. The bond area between the clad coating and the substrate is an $8 \mu \mathrm{m}$ thick thin band of the planar growth. The clad coating has a maximum thickness of about $820 \mu \mathrm{m}$ and is free from pores and cracks. Therefore, an excellent metallurgical bond is created between the coating and the substrate.

The growth morphology of the rapidly solidified coating depends mainly upon both the temperature gradient and the solidification rate [4]. From the coating-substrate interface to the top surface of the coating, the morphology has successively a planar front, followed by cells and dendrites. The planar, cellular and dendritic phases are all f.c.c. $\gamma$-Ni austenite. The interdendritic eutectic consists of $\gamma$ - $\mathrm{Ni}$ and $(\mathrm{Fe}, \mathrm{Cr})_{23} \mathrm{C}_{6}$ carbides. X-ray diffraction shows that the phases of the coating consist of $\gamma-\mathrm{Ni}, \mathrm{TiC}, \mathrm{Cr}_{23}(\mathrm{C}, \mathrm{B})_{6}, \mathrm{Ni}_{5} \mathrm{Si}_{2}$, and $\mathrm{Cr}_{2} \mathrm{~B}$, without the existence of $\mathrm{Ni}-\mathrm{Ti}$ binary system intermetallic phases. The detailed microstructural analyses by transmission electron microscopy (TEM) and X-ray diffraction have been reported elsewhere [5,6]. The results are in agreement with the those of other studies in similar $\mathrm{Ni}$ alloy laser-clad coatings [2,3].

Fig. 2 shows the distribution of TiC particles formed in situ during laser cladding on a microscale relevant to the various growth morphologies of the Ni alloy. In the optical micrograph of Fig. 2(a), the specimen is etched with different etching reagents for the purpose of revealing the cellular growth morphology of the $\mathrm{Ni}$ alloy and the $\mathrm{TiC}$ particles formed in situ. It is observed that $\mathrm{TiC}$ particles are uniformly distributed. Fig. 2(b) shows a scanning electron micrograph of $\mathrm{TiC}$ particles after deep etching in the dendrite growth zone, where the solidification speed of the advancing solid-liquid interface increases. It is noted that a large number of $\mathrm{TiC}$ particles are uniformly distributed in the interdendritic regions, which means that $\mathrm{TiC}$ particles have been trapped by the rapidly advancing solid-liquid interface. The size distribution of the TiC particle is of the order of hundreds of nanometers. Additionally, the volume fraction of the TiC particles in the dendritic zones is clearly enhanced, as compared with that in cellular zones.
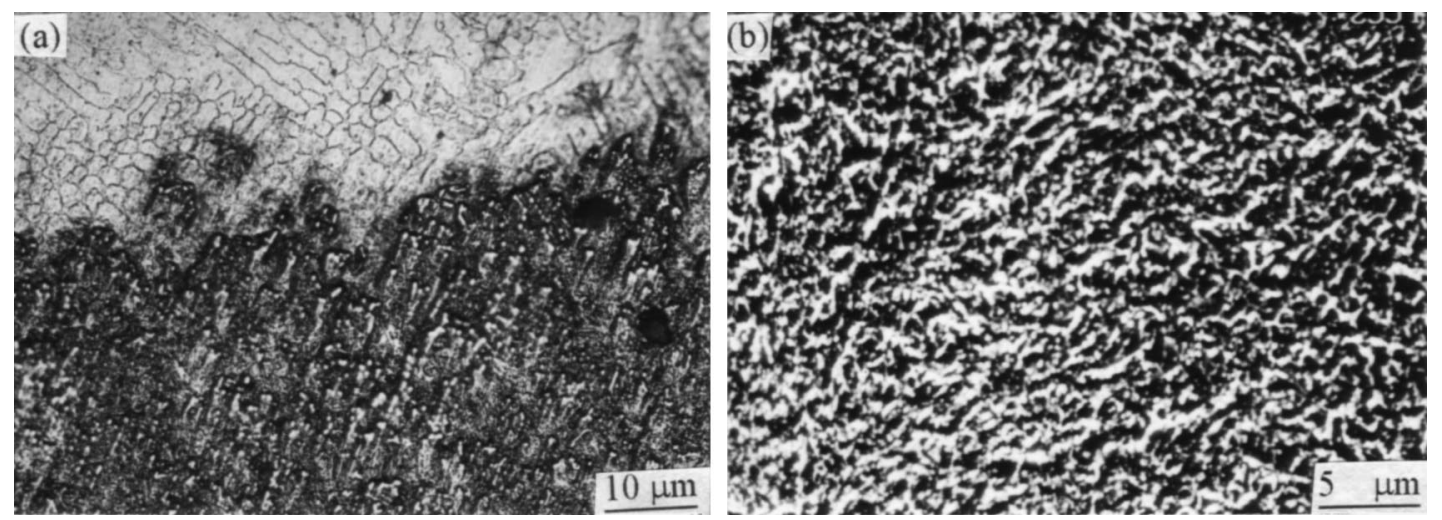

Fig. 2. Optical and scanning electron micrographs showing the uniform distribution of TiC particles reacted in situ in (a) the cellular and (b) the dendritic zones at processing parameters of a $15 \mathrm{~mm} \mathrm{~s}^{-1}$ beam scanning speed, $3 \mathrm{~mm}$ beam diameter and $2 \mathrm{~kW}$ power. 


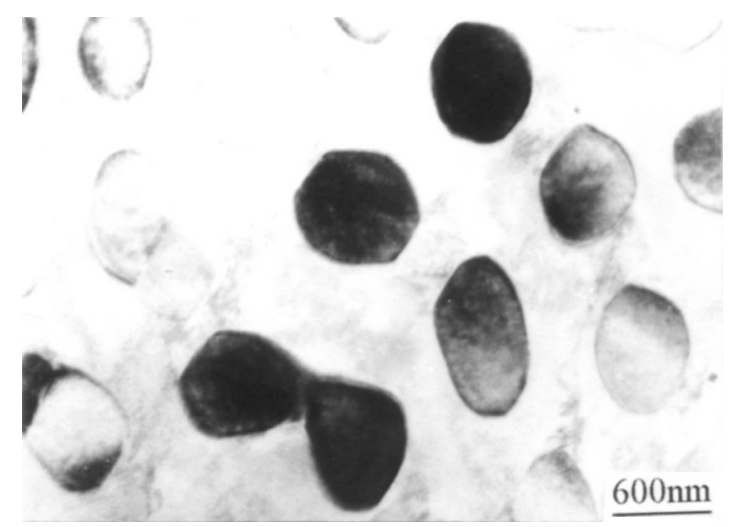

Fig. 3. Bright-field TEM micrograph showing micro-morphology of $\mathrm{TiC}$ in eutectic austenite at processing parameters of a $15 \mathrm{~mm} \mathrm{~s}^{-1}$ beam scanning speed, $3 \mathrm{~mm}$ beam diameter and $2 \mathrm{~kW}$ power.

Fig. 3 is a bright-field TEM micrograph showing TiC particles formed in situ in eutectic $\gamma$-Ni austenite. It can also be seen that most $\mathrm{TiC}$ particles are uniformly distributed.

Fig. 4 is an HREM image illustrating the phase interface between the $\mathrm{TiC}$ and the $\gamma-\mathrm{Ni}$ austenite. It is noted that the interface remains clean and free from any deleterious phase due to interface reactions. Because of both the high solidification speed and the high cooling speed, the interface reaction between the particle and the molten alloy is restrained. This is considered to be one of the main advantages of the interfaces generated in situ. This clean interfacial structure is consistent with that obtained with other in situ processes [7]. Thus, the matrix-TiC has a strong interface bond. In addition, the rapid movement of the solid-liquid interface limits the particle pushing effect and brings about a uniform distribution. Additionally, rapid solidification can also effectively decrease coarsening of particles which is detrimental for the structure-sensitive properties of composites.

In the present method, TiC-reinforced phases are

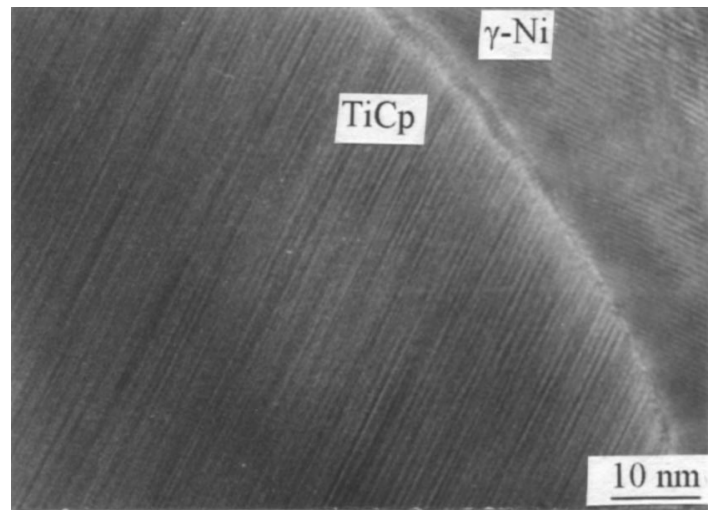

Fig. 4. HREM image showing $\mathrm{TiC}-\gamma$-Ni interface at processing parameters of a $15 \mathrm{~mm} \mathrm{~s}^{-1}$ beam scanning speed, $3 \mathrm{~mm}$ beam diameter and $2 \mathrm{~kW}$ power. introduced into the metal matrix by the direct reaction between titanium and graphite. Therefore, the reinforced phases reacted in situ may be more compatible with the matrix and the phase boundaries may be cleaner as compared with other composites produced conventionally. Meanwhile, because the precipitates formed in situ are often ultra-fine and thermally stable, the composite matrix has sufficient strength to transfer stress.

The beam scanning speed has a key effect on the micro-distribution of TiC particles, as shown in Fig. 5. It can be seen that most of the $\mathrm{TiC}$ particles segregate between dendrite arms because of the solute pushing effect at a $4 \mathrm{~mm} \mathrm{~s}^{-1}$ beam scanning speed. Furthermore, it is important to note that in the experimental range investigated, there exists a critical beam scanning speed, $8 \mathrm{~mm} \mathrm{~s}^{-1}$, corresponding to the transition from trapping to pushing of TiC particles by the advancing solidliquid interface.

The micro-distribution of particles depends mainly upon the interaction between the particles and the advancing solid-liquid interface. This interaction may lead to trapping or pushing of particles by the solidliquid interface. Trapping may bring about a uniform distribution of particles within interdendritic regions whereas pushing results in the segregation at regions finally solidified. The interaction between the particles and the advancing solid-liquid interface has been studied under the condition of equilibrium thermodynamics, i.e. at a very low crystal growth speed [8,9], and, it is widely accepted that there exists a critical speed which corresponds to a transition from pushing to trapping.

Unfortunately, a quantitative or qualitative criterion for such an interaction under rapid solidification conditions has not been established because of the complexity of the thermal physics in the laser-melted pool. Also, the size, morphology, volume fraction and thermal conductivity of the particles and the flow of the matrix have an influence upon particle pushing effects. However, an increase in the local interface solidification speed, which is related to the beam scanning speed, is

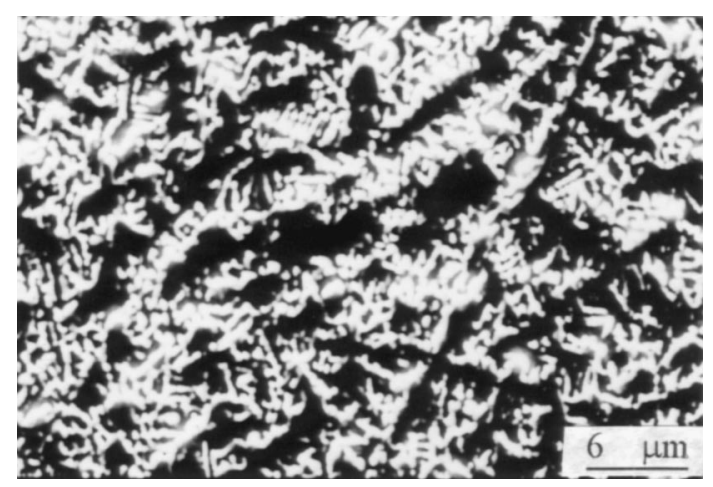

Fig. 5. Scanning electron micrograph showing segregation distribution of $\mathrm{TiC}$ particles in the dendritic zone at processing parameters of a $4 \mathrm{~mm} \mathrm{~s}^{-1}$ beam scanning speed, $3 \mathrm{~mm}$ beam diameter and $2 \mathrm{~kW}$ power. 


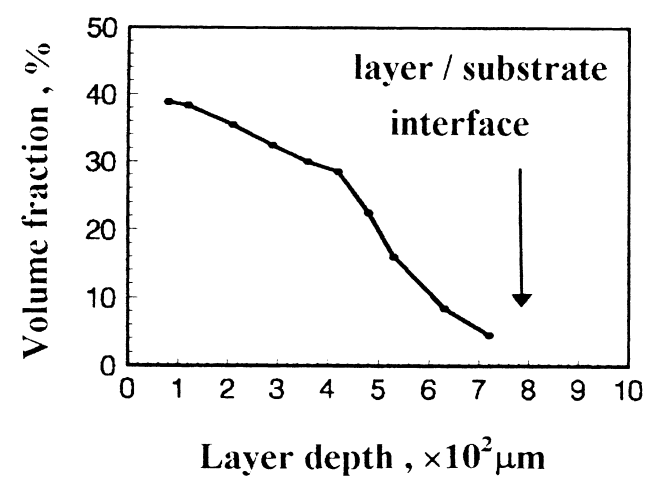

Fig. 6. Gradient distribution of TiC particles with the coating depth at processing parameters of a $15 \mathrm{~mm} \mathrm{~s}^{-1}$ beam scanning speed, $3 \mathrm{~mm}$ beam diameter and $2 \mathrm{~kW}$ power.

considered to have an important effect on particle trapping. Esrstrom et al. [10] and $\mathrm{Li}$ [11] have pointed out that increasing the solidification speed and the cooling speed may weaken or even suppress the particle pushing effects in rapid solidification processing of MMCs. Fulcunaga et al. [12] have confirmed that, under the rapid solidification conditions, there exists a critical speed at which the transition from pushing to trapping occurs. From Figs. 2 and 5, it can be seen that increasing the beam scanning speed has a key effect on restraining the solute pushing effect.

\subsection{Gradient distribution of TiC particles}

It is observed, based upon the image analyses, that the volume fraction of $\mathrm{TiC}$ particles possesses a smooth gradient distribution as a function of the coating depth, as shown in Fig. 6. The volume fraction of TiC particles changes from $1.86 \%$ at the bottom to $38.4 \%$ at the top surface of the layer at a $15 \mathrm{~mm} \mathrm{~s}^{-1}$ scanning speed.The average volume fraction of $\mathrm{TiC}$ in the whole coating is approximately $22.6 \%$, which is smaller than that of the original content in the powder mixture.

The relative lower density of $\mathrm{TiC}$ compared with the Ni alloy will cause a gradient distribution on a macroscale. The differential-density-driven particle movement was also found in previous studies [13,14], where the particles tended to segregate to the upper regions in the particle-reinforced MMC layer. Hu et al. [14] have pointed out that, whenever the liquid viscosity and the time allow, there will be ceramic particulate movement due to the relative densities of the components. Additionally, the convective flow in the liquid will have an effect on the movement of the ceramic particulates. The forces and flow patterns resulting from surface tension gradients will undoubtedly strongly influence the distribution of ultra-fine ceramic reinforcements formed in situ.

Because the cladding coating possesses different microstructural, physical and mechanical characteristics from the substrate materials, the coating-substrate interface can become the main point of failure because of the high stress concentration. The functionally gradient material (FGM), in which the composition, structure and property vary progressively as a function of position, is pursued in materials development in order to avoid the problem due to the interface. Recently, high power $\mathrm{CO}_{2}$ lasers have been used to produce functionally gradient coatings (FGCs) by the successive deposition of several alloyed/clad layers superimposed in a direction normal to the substrate. Jasim et al. [15] have obtained an FGC using three vertically overlapping laser-processed tracks, in which the proportion of $\mathrm{SiC}$ reinforcement increased in steps from 10 to 50 vol.\%. Abboud et al. [16] have also produced FGCs on $\mathrm{Ti}-\mathrm{Al}$ and $\mathrm{Ni}-$ $\mathrm{Al}$ substrates by deposition of superimposed layers with different feed rates. However, the above multilayer coatings consist of essentially discrete layers rather than a smooth gradient of composition and structure. Also, there exist sharp demarcations between the layers, which create sudden changes in mechanical properties across the whole coating.

\subsection{Microhardness and wear property}

Fig. 7 illustrates the hardness variation of a crosssection as a function of the layer depth at processing parameters of a $15 \mathrm{~mm} \mathrm{~s}^{-1}$ beam scanning speed, $3 \mathrm{~mm}$ beam diameter and $2 \mathrm{~kW}$ power. The results shows that there is no sudden change of the microhardness across the whole coating. The highest hardness, $1250 \mathrm{Hv} 0.2$, is at the layer surface, consistent with the volume distribution of TiC particles.

Fig. 8 shows the wear volume, wear rate and friction coefficient of the TiC MMC layer at the same processing parameters, compared with a laser-clad Ni alloy composite layer and the substrate. The TiC MMC layer has the smallest wear volume and also the lowest wear rate. It is noted that the friction coefficients of the TiC MMC layer is only a little higher than that of the $\mathrm{Ni}$ alloy

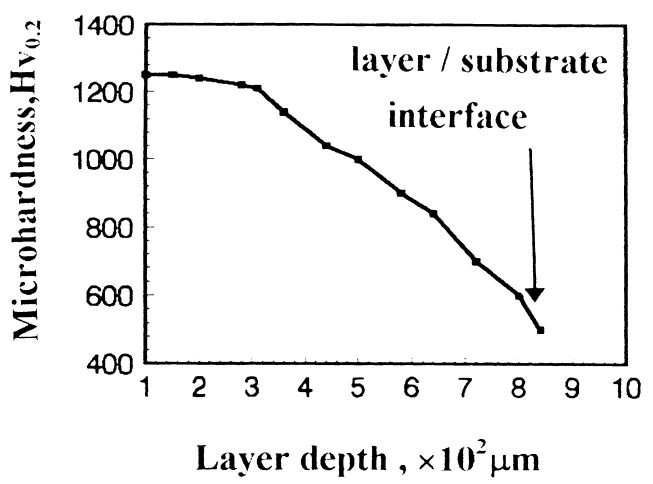

Fig. 7. Microhardness variation with the coating depth at processing parameters of a $15 \mathrm{~mm} \mathrm{~s}^{-1}$ beam scanning speed, $3 \mathrm{~mm}$ beam diameter and $2 \mathrm{~kW}$ power. 


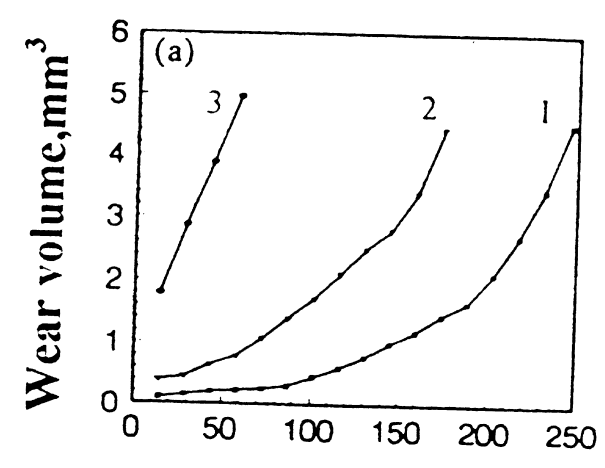

Sliding distance, $m$
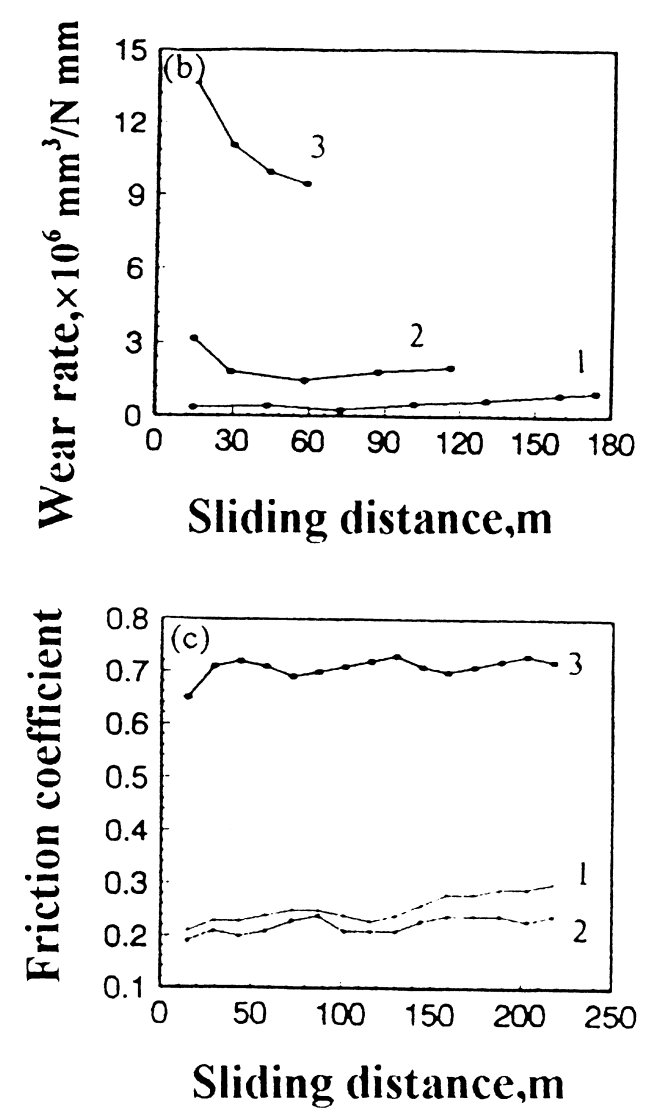

Fig. 8. The variation of (a) the wear volume, (b) the wear rate and (c) the friction coefficient of the coating with the sliding distance at processing parameters of a $15 \mathrm{~mm} \mathrm{~s}^{-1}$ beam scanning speed, $3 \mathrm{~mm}$ beam diameter and $2 \mathrm{~kW}$ power.

layer. Therefore, the TiC-reinforced composite layer may enhance the hardness and wear resistance without evidently increasing the friction coefficient of the layer. Under the present wear conditions, it is expected that a large amount of fine and well-distributed in situ TiC particles with a strong interface bond will certainly enhance the wear properties of the layer effectively. Meanwhile, for the same reason, the in situ MMCs also exhibit improved fatigue and impact wear properties [17].

\section{Conclusions}

(1) A new in situ method has been developed to produce $\mathrm{Ni}$ alloy composite coatings reinforced by in situ reacted $\mathrm{TiC}$ particles with a gradient distribution. The dispersed and ultra-fine TiC particles are formed in situ. The TiC particles are mainly uniformly distributed because of the solute trapping effect.

(2) There exists a critical beam scanning speed which corresponds to the transition from pushing to trapping of particles by an advancing solid-liquid interface.

(3) The TiC particles have a gradient distribution on a macroscale as a result of differential-density-driven and convective flow.

(4) The $\mathrm{TiC}-\gamma-\mathrm{Ni}$ interface generated in situ is found to remain clean and free from any deleterious phase due to interface reactions, and this leads to a strong interfacial bond.

(5) The microhardness of the coating also reveals a gradient variation with the highest value of $1250 \mathrm{Hv} 0.2$ at the surface of the coating.

(6) The wear properties of the coating are significantly enhanced.

\section{Acknowledgements}

This research was supported by the Major Research Foundation of The Chinese Academy of Sciences (KY951-A1-601-03), the National Natural Science Foundation of China (59836220) and the Postdoctoral Research Foundation of China (4868), and their support is grateful acknowledged.

\section{References}

[1] J.H. Abboud, D.R.F. West, J. Mater. Sci. 27 (1992) 4201-4207.

[2] K.P. Kooper, SPIE 957 (1988) 42-47.

[3] J.D. Ayers, T.R. Tucker, Thin Solid Films 73 (1980) 201-207.

[4] A. Frenk, W. Kurz, Lasers Eng. 1 (1992) 193-198.

[5] X.L. Wu, G.N. Chen, Acta Metall. Sin. 34 (1998) 1284-1288.

[6] X.L. Wu, G.N. Chen, Trans. Heat Treat. Met. 19 (1998) 1-8.

[7] T.J. Langan, J.R. Pickens, Scr. Metall. Mater. 25 (1991) $1587-1591$.

[8] D.R. Uhlmann, B. Chalmers, K.A. Jackson, J. Appl. Phys. 35 (1964) 2986-2991.

[9] S.N. Omenyi, A.W. Neumann, C.J. van Oss, J. Appl. Phys. 52 (1981) 789-794.

[10] J.C. Ehrstrom, W.H. Kool, J. Mater. Sci. 23 (1988) 3195.

[11] B.Q. Li, JOM 8 (1995) 13-18.

[12] H. Fulcunaga, S. Komatsu, Y. Kanoh, Bull. Jpn. Soc. Mech. Eng. 26 (1983) 1814-1819.

[13] G. Abbas, D.R.F. West, Wear 143 (1991) 353-363.

[14] C. Hu, L. Barnard, S. Mridha, T.N. Baker, J. Mater. Process. Technol. 58 (1996) 87-95.

[15] K.M. Jasim, R.D. Rawlings, D.R.F. West, J. Mater. Sci. 27 (1992) 1937-1946.

[16] J.H. Abboud, D.R.F. West, J. Mater. Sci. Lett. 13 (1994) $457-460$.

[17] X.L. Wu, Postdoctoral Research Report, Institute of Mechanics, Chinese Academy of Sciences, Beijing, 1998, pp. 75-83. 